\title{
ground water \\ Spatial and Temporal Infiltration Dynamics During Managed Aquifer Recharge
}

\author{
by Andrew J. Racz ${ }^{1}$, Andrew T. Fisher ${ }^{2}$, Calla M. Schmidt ${ }^{2}$, Brian S. Lockwood ${ }^{3}$, and Marc Los Huertos ${ }^{4}$
}

\begin{abstract}
Natural groundwater recharge is inherently difficult to quantify and predict, largely because it comprises a series of processes that are spatially distributed and temporally variable. Infiltration ponds used for managed aquifer recharge (MAR) provide an opportunity to quantify recharge processes across multiple scales under semicontrolled conditions. We instrumented a 3-ha MAR infiltration pond to measure and compare infiltration patterns determined using whole-pond and point-specific methods. Whole-pond infiltration was determined by closing a transient water budget (accounting for inputs, outputs, and changes in storage), whereas point-specific infiltration rates were determined using heat as a tracer and time series analysis at eight locations in the base of the pond. Whole-pond infiltration, normalized for wetted area, rose rapidly to more than $1.0 \mathrm{~m} / \mathrm{d}$ at the start of MAR operations (increasing as pond stage rose), was sustained at high rates for the next $40 \mathrm{~d}$, and then decreased to less than $0.1 \mathrm{~m} / \mathrm{d}$ by the end of the recharge season. Point-specific infiltration rates indicated high spatial and temporal variability, with the mean of measured values generally being lower than rates indicated by whole-pond calculations. Colocated measurements of head gradients within saturated soils below the pond were combined with infiltration rates to calculate soil hydraulic conductivity. Observations indicate a brief period of increasing saturated hydraulic conductivity, followed by a decrease of one to two orders of magnitude during the next 50 to 75 d. Locations indicating the most rapid infiltration shifted laterally during MAR operation, and we suggest that infiltration may function as a "variable source area" processes, conceptually similar to catchment runoff.
\end{abstract}

\section{Introduction and Project Motivation}

Groundwater is essential for meeting fresh water demand worldwide to satisfy urban, agricultural, industrial, and environmental needs, particularly in arid and semiarid parts of the western and southern United States. In California, approximately $40 \%$ of fresh water demand

\footnotetext{
${ }^{1}$ Corresponding author: Department of Earth and Planetary Sciences, University of California, Santa Cruz, Santa Cruz, CA 95064; 831459 2838; fax: 831459 3074; aracz@ucsc.edu

${ }^{2}$ Department of Earth and Planetary Sciences, University of California, Santa Cruz, Santa Cruz, CA 95064. 95076.

${ }^{3}$ Pajaro Valley Water Management Agency, Watsonville, CA

${ }^{4}$ California State University, Monterey Bay, Seaside, CA 93955.

Received February 2011, accepted September 2011.

(C) 2011, The Author(s)

Ground Water (C) 2011, National Ground Water Association.

doi: 10.1111/j.1745-6584.2011.00875.x
}

is met by groundwater during a "normal" year (when hydrologic conditions are consistent with long-term averages), but during dry years groundwater supplies up to approximately $60 \%$ of demand (California Water Plan Update 2009). Increasing population, continuing agricultural and municipal development, and anticipated changes to the regional hydrologic cycle (especially the intensity, location, and seasonal variability of precipitation) all pose challenges for the successful management of water resources; resource managers in many regions will rely more heavily on groundwater in coming decades.

Many groundwater basins in California are overdrafted, such that the combined influence of groundwater pumping and the sum of other inputs and outputs has led to unacceptable harm to environmental resources and systems (Fleckenstein et al. 2004; Reinelt 2005; Harou and Lund 2008). Groundwater overdraft can lead to land subsidence (and an associated loss of storage capacity), sea 
water intrusion, reductions in base flow to streams (sometimes leading to the formation of dry gaps), and reductions in surface water and groundwater quality and the health of aquatic habitat (Zektser et al. 2005; Harvey et al. 2007; Gallardo et al. 2009; Werner and Simmons 2009). To address threats to the environment and water supply associated with overdraft, artificial recharge of groundwater is gaining popularity as a water management tool in California and throughout the world.

Artificial recharge comprises a series of strategies and techniques for increasing the flow of water into an aquifer, often using excess flows in streams or other surface channels, agricultural return flows, or treated waste water (Bouwer 2002; Greskowiak et al. 2005; Prommer and Stuyfzand 2005; Massmann et al. 2008). Recharge can be achieved using injection wells, bank filtration in streams, and infiltration ponds. Artificial recharge achieved using surface infiltration basins is commonly referred to as "managed aquifer recharge" (MAR). Successful application of MAR generally requires maintaining relatively high hydraulic conductivity in shallow soils, so that infiltration conveys water efficiently from the surface to the subsurface during regular periods of system operation. Rates of infiltration during MAR are often rapid initially, but infiltration generally slows over time as a result of physical, chemical, and biological processes (Bouwer et al. 2001).

MAR projects are often operated in arid to semiarid climates, where there is a thick vadose zone between the infiltration basin and the underlying aquifer (Heilweil et al. 2007; Izbicki et al. 2008). In some cases, the depth to the regional water table is tens to hundreds of meters. Where there is a thick vadose zone, the soil above the water table may never become fully saturated, even during long periods of MAR operation. Instead, a localized saturated zone with an "inverted water table" will form beneath the infiltration pond, and a thicker layer of largely unsaturated conditions will remain between the inverted water table and the regional water table, even as infiltrating water flows rapidly downward. Groundwater flow in this soil zone occurs either as unsaturated flow, governed by the physics of multiphase transport, or as saturated flow along spatially limited, preferential flow paths.

Not all of the water infiltrated during MAR becomes recharge. Some infiltration becomes trapped in the vadose zone as soil water, particularly infiltration that occurs near the start of the MAR operation season, and can be returned to the atmosphere by evaporation and transpiration. Quantifying MAR infiltration is an important step in determining the contribution of MAR to improving groundwater resources, and generally provides an upper limit on the extent of recharge. In addition, researchers and water managers need to understand the distribution of infiltration within MAR ponds, spatially and temporally, so as to resolve the extent of causes of reductions to MAR efficiency. This is particularly important if MAR is linked to low-impact development, storm water capture, passive discharge from adjacent waterways, or other mechanisms that make it difficult to accurately determine the rate of inflow to a MAR infiltration system. Resolving temporal and spatial variability in infiltration is also important for quantifying the influence of MAR on the delivery of nutrients and other contaminants to underlying aquifers, and associated changes to groundwater quality, and provides insight as to the nature of infiltration and recharge processes in general.

In this study, we compare whole-system and pointspecific infiltration rates and their spatial and temporal variability within an operating MAR recharge pond Whole-system and point-specific infiltration rates were determined using mass balance and time series thermal techniques, respectively. Point-specific infiltration rates were combined with independent measurements of saturated pressure gradients to quantify the magnitudes, locations, and timing of changes to the hydraulic conductivity of shallow soils at the field site. Additional studies are exploring the processes responsible for spatial and temporal heterogeneity in infiltration and hydraulic conductivity reported in this study, and quantify the influence of MAR infiltration on groundwater quality (Schmidt et al. 2011a).

\section{Experimental Site and Methods}

This study focuses on samples and data collected during the 2007 to 2008 water year (October 1, 2007 to September 30, 2008) in and around the Harkins Slough MAR (HS-MAR) pond, an infiltration basin on the western side of the Pajaro Valley, central coastal California (Figure 1). The recharge pond has an area of 3 ha and occupies a modified natural depression overlying Holocene alluvial and fluvial deposits and dune sands (Hanson 2003). Annual precipitation across the Pajaro Valley averages $50 \mathrm{~cm} /$ year, with more than $90 \%$ of precipitation falling between December and April. Many streams and wetlands in this region fill and flood during the rainy season, but become dry later during the water year.

The HS-MAR project is operated by the Pajaro Valley Water Management Agency, which is permitted to divert up to $2.5 \times 10^{6} \mathrm{~m}^{3}$ of surface runoff from Harkins Slough during the rainy season when slough levels and water quality are sufficiently high. Water diverted from the slough is passed through a sand pack filter, then pumped through a $1.5 \mathrm{~km}$ pipeline to a MAR infiltration pond (Figure 1). The maximum water depth in the pond is approximately $6 \mathrm{~m}$ when the pond is full. Groundwater beneath the MAR pond is perched atop a fine-grained unit approximately 20 to $30 \mathrm{~m}$ below the ground surface. Before seasonal diversion from the slough begins, the local water table is approximately 15 to $20 \mathrm{~m}$ below the base of the pond. When the infiltration pond is filled and MAR peaks, groundwater levels in monitoring wells surrounding the pond typically rise by 3 to $6 \mathrm{~m}$. Recovery wells adjacent to the pond are used to withdraw shallow groundwater, which is blended with other water supplies and distributed by pipeline to surrounding agricultural 

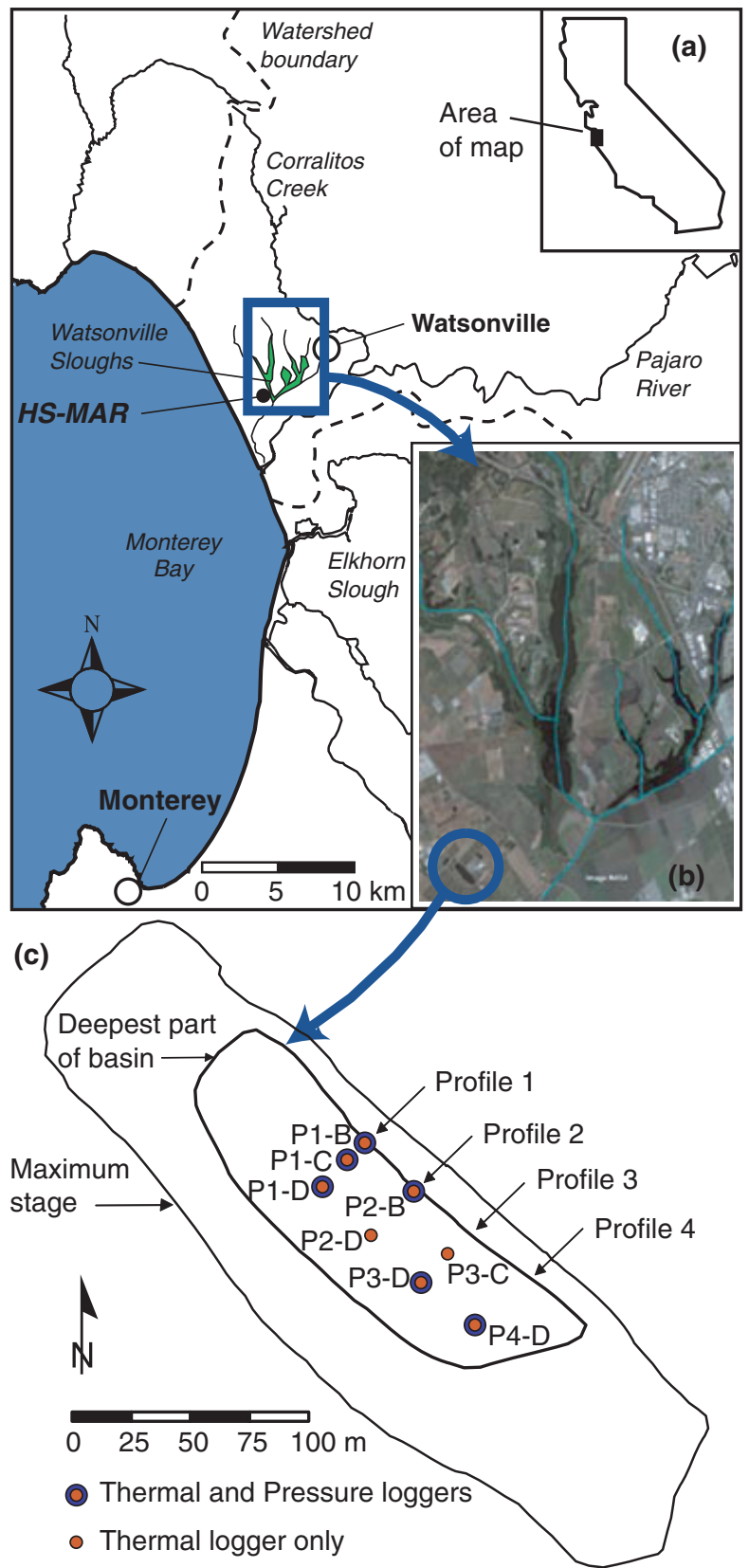

Figure 1. Site maps. (a) Project location in central coastal California, United States. (b) Inset aerial photo showing regional sloughs (wetlands) and location of MAR pond. (c) Distribution of sampling and instrumentation locations in the MAR pond presented in this study. Diverted slough water used for MAR enters the pond adjacent to location P2-B. Soil samples were collected along Profiles 1 to 4, and at additional locations across the MAR pond.

lands. Water supplied by the HS-MAR system allows reduced usage or retirement of coastal wells tapping a deeper, regional aquifer that is impacted by sea water intrusion.

The HS-MAR pond was surveyed, soils were sampled, and instruments were installed prior to the start of water diversion and infiltration in 2008. A digital elevation model (DEM) for the pond was created with a high-resolution laser scanning survey referenced to mean sea level. Benchmarks located adjacent to the pond were used to determine relative and absolute elevations of instrument, sampling and monitoring points across the pond. Soils were collected using a hand auger to a maximum depth of $2.5 \mathrm{~m}$ below ground surface along a series of transects across the pond (Figure 1c). Soil samples were arranged on a sample description board in the field to recapitulate local stratigraphy, document color, classify texture, and note lithologic changes. Soil columns were photographed and subsampled $\left(20\right.$ to $\left.40 \mathrm{~cm}^{3}\right)$ for grain size, organic carbon, and other analyses at regular intervals. Soil grain size distribution was determined on selected samples following digestion in peroxide (to remove organic material), freeze drying, and homogenization to produce a representative mixture. Grain size analyses were completed with a Beckman Coulter LS 13320 laser diffraction particle size analyzer following suspension of digested soils in water and deflocculation with sodium metaphosphate. Soil porosity values were determined empirically based on grain size distribution data.

Whole-pond infiltration rates were calculated by mass balance:

$$
I=D+P-E-\Delta V,
$$

where net infiltration (I) comprises the sum of the following terms (all determined as positive values except as indicated):

- Diversions $(D)$ from Harkins Slough, measured hourly.

- Precipitation $(P)$ into the pond, measured hourly on site with a tipping bucket rain gauge, and verified using public records acquired from the California Irrigation Management Information System (CIMIS), Watsonville West Station 209, located $2.6 \mathrm{~km}$ north of the field site. Although the pond is located within a natural depression, sandy soils in the region surrounding the pond have a high infiltration capacity, and we observed little hill-slope runoff into the pond.

- Evaporation $(E)$ from the pond, determined hourly at CIMIS Station 209, based on calculations of potential evapotranspiration $(P E T)$. In later project years, we collected meteorological data at the HS-MAR pond (temperature, net solar radiation, and wind speed) and compared longer-term open water evaporation calculations (Winter et al. 1995) to CIMIS-derived PET values, with consistent results between these methods.

- Changes in storage in the pond $(\Delta V)$ were determined every $15 \mathrm{~min}$ using an autonomous pressure gauge deployed in a stilling well in combination with the pond DEM. Absolute pressure records were corrected for barometric variations, also measured on site, and related to pond volume, surface area, and wetted area based on field observations of pond stage combined with the pond DEM. Values of $\Delta V$ were positive when the pond volume increased, and negative when the pond volume decreased. 
HS-MAR water budget calculations were completed at 15 - to 60-min intervals, then combined to determine daily mean flow rates and storage changes, allowing for comparison with daily point-specific infiltration rates based on thermal methods, described later. Daily pond infiltration values (units of $\mathrm{m}^{3} / \mathrm{d}$ ) were normalized by wetted area (varies with pond stage) to derive specific infiltration rates for the whole pond (units of $\mathrm{m}^{3} / \mathrm{m}^{2} / \mathrm{d}=$ $\mathrm{m} / \mathrm{d}$ ). These values were divided by a porosity value typical of shallow soils below the pond to convert to average linear velocity, which allows a direct comparison between whole-pond and point-specific infiltration rates.

Point-specific infiltration rates within saturated soils below the HS-MAR pond were determined using heat as a tracer of fluid flow (Constantz et al. 1994; Anderson 2005) based on time series analysis of subsurface thermal data (Hatch et al. 2006). Daily fluctuations in the temperature at the base of the pond (typically 1 to $3{ }^{\circ} \mathrm{C}$, even on cloudy days), propagate downward into the subsurface as thermal waves by conductive, advective, and dispersive processes. Daily temperature variations become reduced in amplitude and shifted in phase as they penetrate to greater depths (Figure 2), and the magnitude of amplitude reduction and phase shift are a function of infiltration rate. Time series records of temperature below the pond are filtered to extract this diurnal signal, pairs of subsurface sensors are analyzed to resolve the amplitude reduction and phase shift once per day, and these values are used to solve for fluid infiltration rates based on a one-dimensional (vertical) conservation-of-heat equation. Application of this method depends on the spacing between pairs of subsurface sensors, not their absolute depths, so it is relatively insensitive to sedimentation or scour (e.g., a moving thermal boundary condition). This method has high sensitivity and a relatively wide dynamic range, being capable of quantifying rates from more than $10 \mathrm{~m} / \mathrm{d}$ to less than $0.01 \mathrm{~m} / \mathrm{d}$ (Hatch et al. 2006).

Subsurface thermal data were recorded at eight locations in 2008, as part of four instrument and soil/fluid sampling transects (Figure 1c). Autonomous thermal probes were deployed on cables suspended inside $3.8-\mathrm{cm}$ diameter polyvinyl chloride (PVC) tubes. PVC tubes were screened at depths of approximately 70 to $90 \mathrm{~cm}$ below the base of the pond, so that they could also function as piezometers, and six of the tubes were instrumented with autonomous pressure loggers. Tubes were installed in boreholes excavated by hand auger, and a coarse sand filter (grain diameter $=0.7$ to $1.7 \mathrm{~mm}$, well rounded, more than $97 \%$ silica) was installed around the screen and capped with a $10-\mathrm{cm}$ thick bentonite seal. The shallow annulus of each borehole was backfilled with native soil, and a second bentonite seal was placed at the ground surface to prevent seepage along the sides of the tube. Following installation, piezometers were filled with water and developed by hand with a surge block to ensure good communication with the formation surrounding the screen, then instrumented with sensors. During normal MAR pond operations, tubes remained filled with water when the depth of the inverted water table below the pond base was below the base of the piezometer screens. Times when the soils around the screens were unsaturated were readily apparent on temperature and pressure records. Thermal data from inside piezometers are interpreted to be representative of conditions in adjacent soils when tubes were filled with water, and infiltration rates were interpreted only when soils surrounding the sensors were saturated. The relatively high thermal conductivity of water allows for this approach, provided there is a good contact between the PVC tubing and the formation and that the sampling frequency is significantly longer than the thermal time
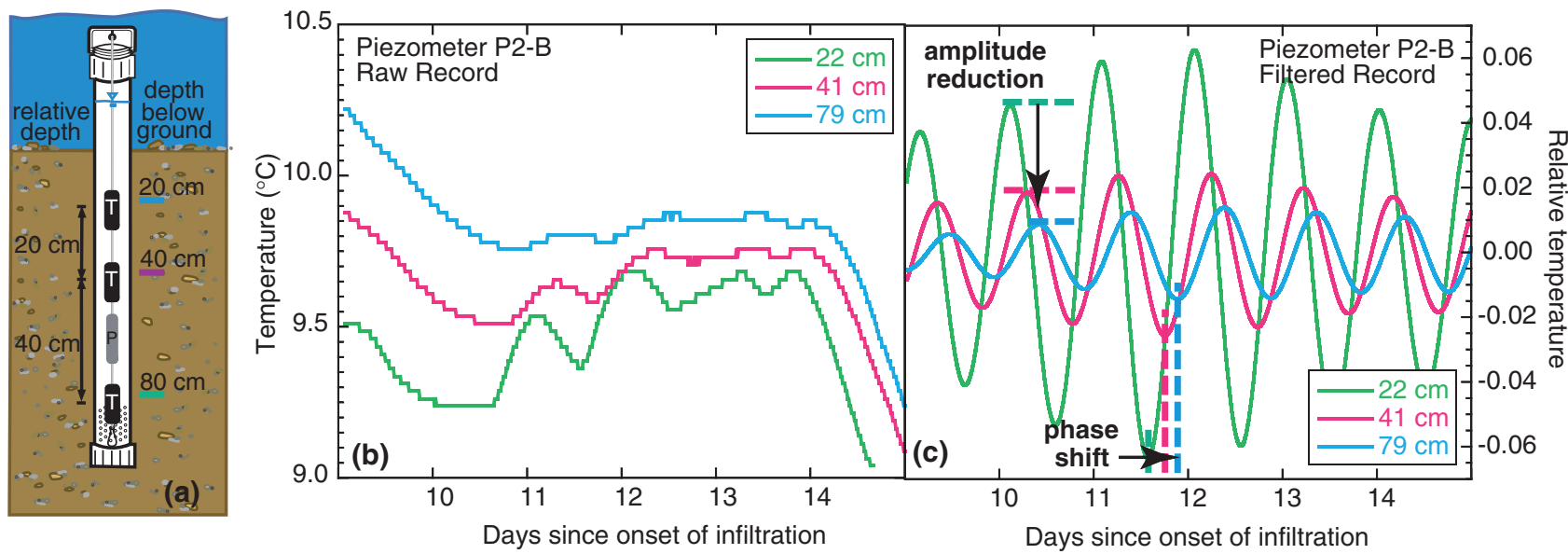

Figure 2. Illustration of thermal method used to assess point-specific infiltration rates (Hatch et al. 2006). (a) Three thermal loggers and one pressure logger are suspended within a PVC pipe, screened at the base and sealed at top. (b) Raw thermal record for piezometer P2-B showing 15-min data collected when the piezometer was filled with water and the shallow subsurface sediments were fully saturated. (c) Filtered thermal record for the same piezometer and time period, showing just the diurnal signal. Note difference in temperature scale compared to panel (b), and amplitude reduction and phase shift with depth below the base of the pond. 
constant of the installation, in this case 5 to 6 min (Ronan et al. 1998; Constantz et al. 2001; Cardenas 2010).

Temperature was recorded at 15-min intervals using autonomous sensors and data loggers having a resolution of $0.02{ }^{\circ} \mathrm{C}$, and pressure was measured at 30 -min intervals with a resolution of $0.04 \mathrm{kPa}$. Filtering of time series thermal records to resolve diel temperature variations results in resampling and generation of a higher resolution time series, with variations on the order of $0.001{ }^{\circ} \mathrm{C}$ being readily apparent in processed records (Figure 2c; Hatch et al. 2006). Thermal loggers were deployed at depths of approximately 20, 40, and $80 \mathrm{~cm}$ beneath the pond-sediment interface. Distances between thermal loggers were measured to the nearest centimeter, as were geometrical parameters for each PVC tube (total depth, screened depth, and riser height). Ground surface elevations at each tube location were surveyed using a laser totaling station and referenced to mean sea level, the same datum used to measure and record pond stage. Processing of thermal data resulted in daily point-specific infiltration rates at each instrument location.

\section{Results}

Shallow soils sampled from the upper $2.5 \mathrm{~m}$ below the base of the pond comprised $80 \%$ to $95 \%$ fine sand, $3 \%$ to $12 \%$ silt, and $1 \%$ to $7 \%$ clay. Most soils samples were classified as silty sand, although there were subtle differences in grain size distribution across the pond and occasional thin layers distributed with depth having higher contents of silt- and clay-sized material. Samples from Profiles 1 and 2 tended to be the coarsest overall (generally less than $10 \%$ combined silt and clay), with slightly higher silt and clay fractions found in samples from Profiles 3 and 4 (up to $20 \%$ silt and clay). Sediment porosity was generally calculated to be $35 \%$ to $40 \%$.

Daily water budget calculations show that diversions from Harkins Slough $(D)$ comprised the greatest source of inflow to the pond, reaching a maximum value near $2 \times 10^{4} \mathrm{~m}^{3} / \mathrm{d}$. Daily precipitation $(P)$ never exceeded $2 \%$ of daily diversions, and was less than $1 \%$ of total inputs for the vast majority of the MAR operating period. Infiltration was the primary outflow from the pond, accounting for $98 \%$ of total season inflows $(D+P)$. Evaporation never exceeded $1 \%$ of infiltration until late in the operating period (after d 110), when the rate of infiltration was greatly reduced.

Whole-pond mass balance calculations indicate that average-specific infiltration rates were highest during the first month of MAR operations, sometimes exceeding $1 \mathrm{~m} / \mathrm{d}$ (Figure 3a). Infiltration rates during this initial period correlate strongly with pond stage $(R=0.73$; Figure $3 \mathrm{~b}$ ). Abrupt decreases in the rate of diversions into the pond on operating d 12 and 25 correspond to rapid lowering of pond stage and thus the hydraulic gradient driving infiltration. Later in the season, the pond stage and infiltration rate became decoupled, with stage remaining relatively high and infiltration decreasing approximately from 1.0 to $0.3 \mathrm{~m} / \mathrm{d}$, where it remained for the next $60 \mathrm{~d}$.
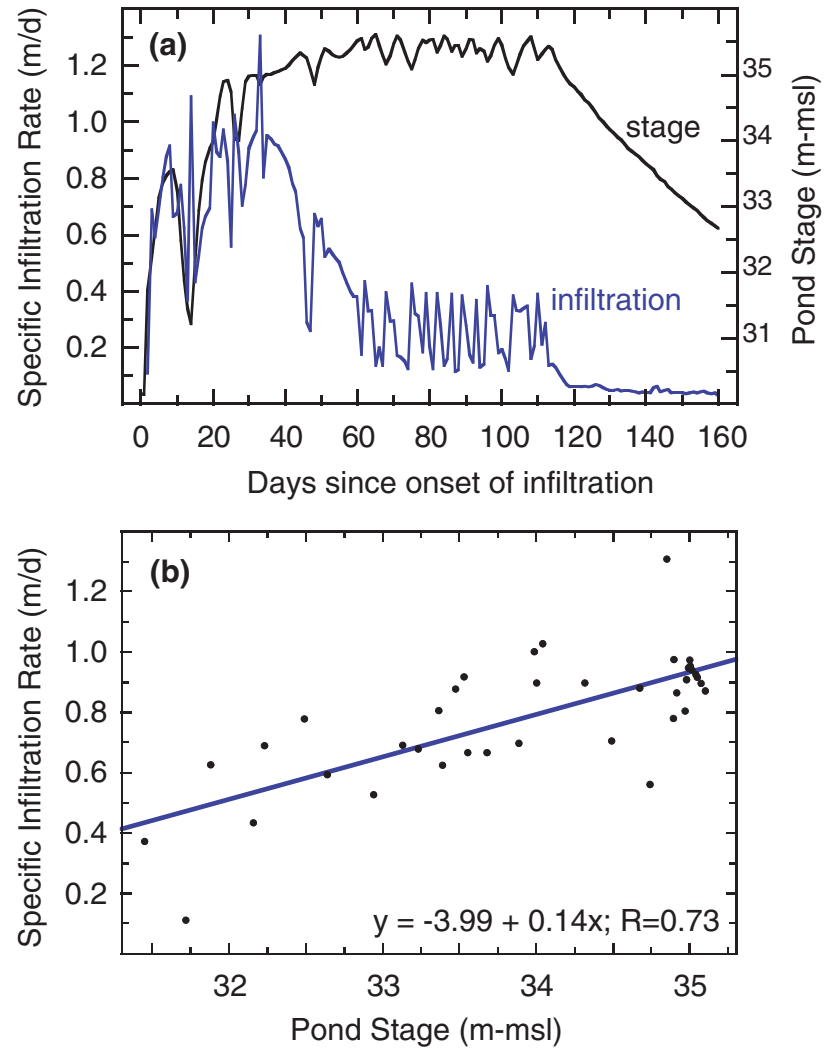

Figure 3. (a) Whole-pond average infiltration rates, derived from mass balance calculations, plotted with pond stage during the full 2008 operating season. (b) Linear regression of infiltration rate vs. stage for the first $40 \mathrm{~d}$ of (a). Infiltration and stage are positively correlated during this period.

Stage dropped rapidly after seasonal diversions ended around $\mathrm{d} 115$, and whole-pond infiltration decreased to less than $0.1 \mathrm{~m} / \mathrm{d}$, where it remained for the last $45 \mathrm{~d}$ of MAR operation (Figure 3a). There were multiday variations in specific infiltration rates measured between d 60 and 110, mainly as a result of how higher resolution data were aggregated to calculate daily infiltration values, but these variations were small in comparison with longerterm trends.

Analyses of subsurface thermal records demonstrate that seepage was heterogeneous in time and space across the bed of the MAR pond through the 2008 operating season. In most cases, infiltration at individual thermal installations followed a pattern similar to that of the whole pond, with an initial increase to a maximum infiltration rate, lasting 20 to $40 \mathrm{~d}$, followed by a longer period of declining infiltration rates (Figure 4a). Infiltration rates along Profile 1 (northwest end of the pond, Figure 1c) were initially the greatest, rising rapidly to more than $1 \mathrm{~m} / \mathrm{d}$, but subsequently decreasing such that they were below the whole-pond infiltration rate after $15 \mathrm{~d}$, and were the lowest measured by $\mathrm{d} 40$. In contrast, infiltration rates along Profile 4 (southeast end of the pond, Figure 1c) were initially just 0.2 to $0.3 \mathrm{~m} / \mathrm{d}$, but rose slowly throughout the operating season, eventually reaching $0.6 \mathrm{~m} / \mathrm{d}$ after $110 \mathrm{~d}$ of infiltration. Infiltration rates along 


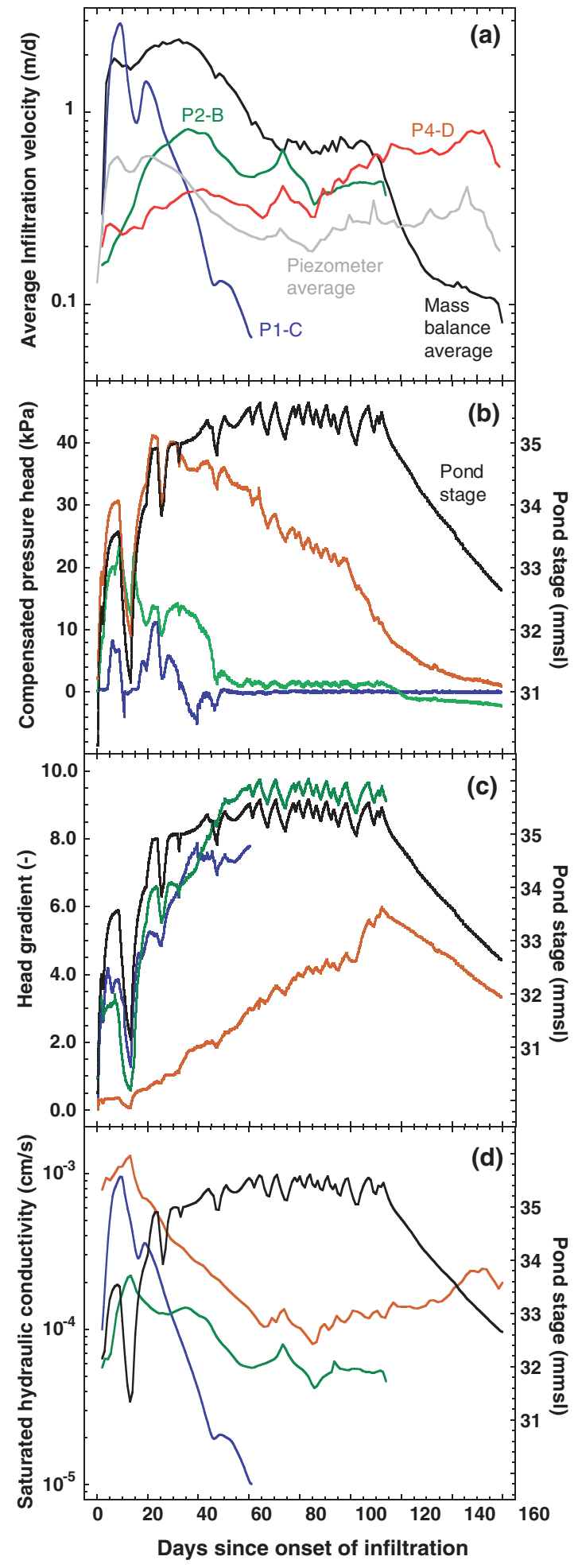

Figure 4. Plots of (a) thermally derived infiltration rates, (b) subsurface pressure, (c) head gradient, and (d) saturated hydraulic conductivity within the upper $1 \mathrm{~m}$ of soil below the base of the MAR infiltration pond, for locations P1-C, P2-B, and P4-D. Measurement locations are shown in Figure 1c. Whole-pond specific infiltration rate and eight-piezometer average rate are plotted for comparison in (a). Pond stage is plotted for reference in (b) through (d). Data sets (a) and (d) were calculated as daily means, then smoothed using a 7-d moving average.
Profile 2, positioned between Profiles 1 and 4 (Figure 1c) represented an intermediate case (Figure $4 \mathrm{a}$ ). The daily means of all point-specific infiltration rates fall below the whole-pond values by a factor of two to four. This suggests that the thermal probes were disproportionately located where infiltration rates were comparatively low.

Subsurface pressure records (corrected for local barometric pressure) illustrate how saturation conditions varied throughout the 2008 MAR operating season (Figure 4b). Pressure rose most rapidly during the first part of MAR operation and tracked pond stage most closely along Profile 4, where infiltration was initially slowest. Pressure rose initially along Profiles 1 and 2 as well, but the start of the pressure rise was delayed by several days and occurred more slowly, never reaching the peak observed along Profile 4. This occurred in part because Profile 4 is in a deeper part of the pond (2.0 to $2.5 \mathrm{~m}$ deeper than Profiles 1 and 2), but also indicates that it was more difficult to maintain saturated conditions along Profiles 1 and 2 within the shallowest $1 \mathrm{~m}$ of soil. In fact, pressures became negative (less than atmospheric) for brief periods early in the operating season along Profile 1 , and late in the season along Profile 2. Negative pressures occurred in soils below the pond when the rate of infiltration from above was exceeded by the rate of deeper percolation, allowing the shallow soil to drain from below. Sustaining negative pressures for brief periods below the pond also required that shallow, unsaturated soils be decoupled from the atmosphere. Atmospheric pressures returned to Profile 1 after $50 \mathrm{~d}$ of operation, indicating that unsaturated conditions extended to the edge of the pond in this area.

Subsurface pressure and pond stage records were combined during times when the shallow soils were saturated to determine head gradients between the base of the pond and the screened depths of the piezometers (center of screens $\sim 80 \mathrm{~cm}$ below pond base) (Figure $4 \mathrm{c}$ ). Some measured gradients, particularly along the initially faster infiltrating Profiles 1 and 2, were very large (approaching 10) and nearly always exceed the canonical (steady-state) maximum natural value of 1 (Scanlon et al. 2002). The elevated gradients likely resulted from a combination of high pond stage and low (but positive) pressures in the shallow subsurface, when the transition from saturated to unsaturated conditions occurred just below the piezometer screens.

We calculate daily, point-specific values of saturated soil hydraulic conductivity by combining infiltration rates with subsurface head gradients, the same approach applied recently to streambed measurements (Figure $4 d$; Hatch et al. 2010). At all locations where we measured both infiltration rates and head gradients, there was an initial period of rapidly increasing saturated hydraulic conductivity, lasting 7 to $15 \mathrm{~d}$, followed by a larger decrease in saturated conductivity lasting 50 to $75 \mathrm{~d}$. The subsequent conductivity decline was most rapid and extensive along Profile 1, where initial hydraulic conductivity values in excess of $10^{-3} \mathrm{~cm} / \mathrm{s}$ (1 darcy) decreased by two orders of magnitude. During this 
same period, measured flow rates decreased from more than $1 \mathrm{~m} / \mathrm{d}$ to just over $0.1 \mathrm{~m} / \mathrm{d}$, after which the soil around Profile 1 piezometers transitioned from saturated to unsaturated conditions. Saturated hydraulic conductivity declined by an order of magnitude at the same time along Profile 4, but there was a simultaneous (and proportionately larger) increase in the head gradient along this profile (Figure 4c), which explains why the infiltration rate increased at the same time (Figure 4a). Once again, data from Profile 2 indicate intermediate conditions, both a lower initial saturated hydraulic conductivity, and a smaller decrease with time during the first $70 \mathrm{~d}$ of MAR operation.

Saturated hydraulic conductivity could not be determined for Profile 1 after approximately $60 \mathrm{~d}$ of MAR operation and for Profile 2 after $120 \mathrm{~d}$ of MAR operation because unsaturated conditions "decoupled" the hydrostatic head at the base of the pond from the partly drained soil below the inverted water table, preventing reliable application of Darcy's law. Unsaturated conditions were readily apparent on both pressure and temperature records recovered from $\mathrm{PVC}$ tubes along these profiles, creating pressure values $\leq 0 \mathrm{kPa}$ (relative to atmospheric) and diel temperature oscillations having a much higher amplitude than those measured when temperature sensors were in a fluid-filled tube.

\section{Discussion and Conclusions}

We were surprised by the extent of spatial and temporal variability in infiltration rates documented in this study. Our initial assessment of shallow soils was that they were relatively homogeneous, being mainly silty sand, but relatively small differences in the percentage of fine material can have a large influence on saturated hydraulic conductivity, and on saturation and drainage properties. The significance of variable infiltration is most apparent when temporal data from the HS-MAR pond are contoured and viewed as a function of time since the start of MAR operations (Figure 5). The most rapid infiltration occurred initially near the northwestern side of the pond, but infiltration rates in this area decreased at the same time that infiltration rates increased near the southeastern side of the pond. In effect, the locus of the fastest infiltration, which would contribute most to increasing the saturation of underlying soils (and presumably to recharging the underlying aquifer), swept across the pond from northwest to southeast. The center of the most rapid infiltration migrated at a time-averaged rate of approximately $2 \mathrm{~m} / \mathrm{d}$, before dissipating late in the MAR operating season. These changes in infiltration rates were often associated with quantitative changes in saturated hydraulic conductivity.

Like many such systems, the HS-MAR pond accumulates fine-grained sediments during each period of system operation. Sources of sediment to the pond may include the suspended load in diverted water (generally kept low by filtering during diversion), hill-slope erosion, and overflow from adjacent agricultural fields during large

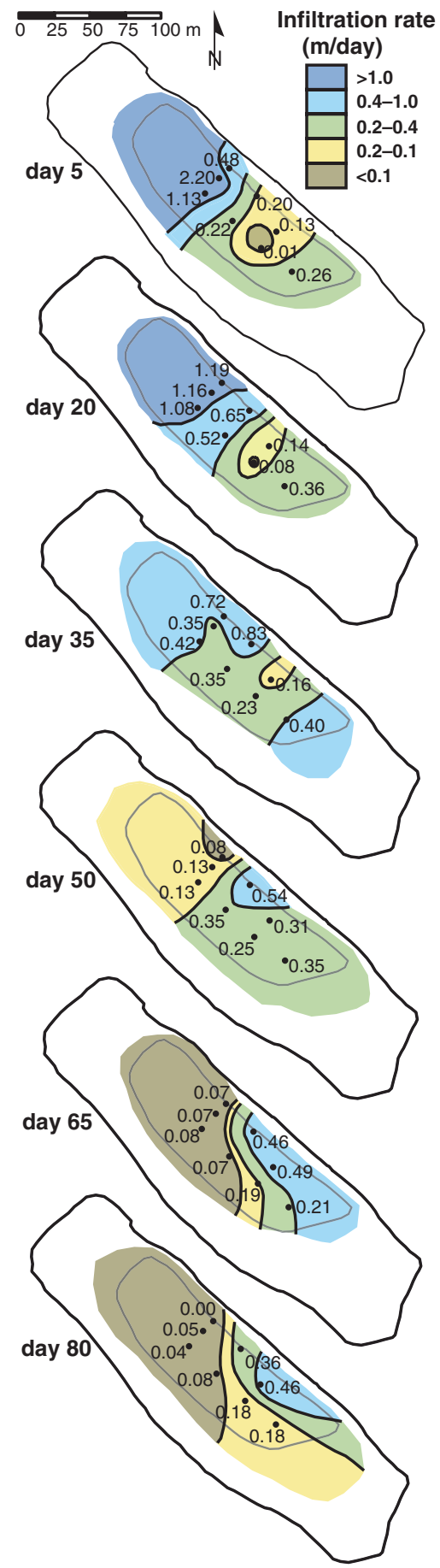

Figure 5. Posted contour plots (hand-drawn) showing rates and the spatial distribution of infiltration at 15-d intervals during the first $80 \mathrm{~d}$ of the $2008 \mathrm{HS}-\mathrm{MAR}$ operating season. Contours that extend beyond the posted data values are extrapolated, but the transition in infiltration rates near the central part of the pond is well defined by the data.

precipitation events. The HS-MAR pond is scraped at the end of each operating season to restore rapid infiltration properties, and additional work is needed to assess the extent to which lower infiltration rates, and disparate patterns of falling and rising saturated hydraulic conductivity, may result from sediment accumulation, sediment penetration, or biofouling. Similarly, work is needed to 
assess whether the initial rise in saturated hydraulic conductivity in shallow soils (Figure 4d) resulted mainly from establishment and deepening of the shallow water table, flushing of fine grains from soil pores, or other processes.

Hydrologists have used the variable source area (VSA) concept for decades to understand spatial and temporal patterns of catchment runoff (Dunne and Black 1970; Hoover 1990; Quinn and Beven 1993). The VSA concept is based on the observation that different parts of a catchment can contribute different amounts of runoff at different times during precipitation events. This study suggests that the variable source concept might be usefully extended to infiltration (and perhaps groundwater recharge as well), as a framework for describing and understanding spatial and temporal variability. The lateral migration of the infiltration peak was assessed using data collected from mainly the upper $1 \mathrm{~m}$ of soil below this MAR pond, but we have not presented information on deeper conditions and processes. Additional investigation, water chemical analyses, and modeling will be necessary to assess the extent to which spatial and temporal patterns of shallow infiltration were expressed as groundwater recharge at depth.

Quantifying the nature, spatial extent, and temporal development of decreases in hydraulic conductivity at the base of MAR ponds is a crucial step in designing and operating these systems so as to maximize benefit to limited (and often fragile) aquatic resources. In the current case, options are being explored for reducing sediment load into the pond in an effort to maintain operational efficiency for a longer time during the MAR season. Additional studies link local infiltration rates to changes in nitrate load (Schmidt et al. 2011a, 2011b), which could be important for understanding why some recharge systems are more effective than others in improving water quality. Studies of MAR ponds also present opportunities to quantify and understand linked physical, chemical, and biological processes that may occur during infiltration and recharge in general. It remains to be determined if the variable infiltration area concept documented in the HS-MAR pond might apply to other MAR systems and within natural catchments more broadly. The use and comparison of system averaged and point-specific tools for measuring infiltration processes and properties across a range of spatial and temporal scales will allow a broader assessment of these conditions and their impacts on water resources.

\section{Acknowledgments}

We thank the Pajaro Valley Water Management Agency for their prescient stewardship, and cooperative and collaborative efforts, in operating and providing access to the Harkins Slough Managed Aquifer Recharge system. We are grateful for technical and field support provided by Dan Sampson, Rob Franks, Bruce Daniels, Nic Massetani, and Joanna Hoffman. Heather Savage, Nicholas van der Elst, and Emily Brodsky helped with acquisition and processing of LiDAR data to produce the DEM. This research was financed by graduate fellowships from the Science, Technology, Engineering, Policy, and Society Institute at UC Santa Cruz and the U.S. Environmental Protection Agency, and grants from the UC Santa Cruz Committee on Research, the California Water Resources Control Agency (through the Santa Cruz County Resource Conservation District, UCSCPAJARO013107), and the National Institutes for Water Resources (08HQGR0054).

\section{References}

Anderson, M.P. 2005. Heat as a ground water tracer. Ground Water 43, no. 6: 951-968.

Bouwer, H. 2002. Artificial recharge of groundwater: Hydrogeology and engineering. Hydrogeology Journal 10, no. 1: $121-142$.

Bouwer, H., J. Ludke, and R.C. Rice. 2001. Sealing pond bottoms with muddy water. Ecological Engineering 18, no. 2: $233-238$.

California Water Plan Update 2009. State of California, Department of Water Resources. Bulletin 160-09.

Cardenas, M.B. 2010. Thermal skin effect of pipes in streambeds and its implications on groundwater flux estimation using diurnal temperature signals. Water Resources Research 46: W03536.

Constantz, J., D. Stonestrom, A.E. Stewart, R. Niswonger, and T.R. Smith. 2001. Analysis of streambed temperatures in ephemeral channels to determine streamflow frequency and duration. Water Resources Research 37, no. 2: 317-328.

Constantz, J., C.L. Thomas, and G. Zellweger. 1994. Influence of diurnal variations in stream temperature on streamflow loss and groundwater recharge. Water Resources Research 30, no. 12: 3253-3264.

Dunne, T., and R.D. Black. 1970. Partial area contributions to storm runoff in a small New England watershed. Water Resources Research 6, no. 5: 1296-1311.

Fleckenstein, J., M. Anderson, G. Fogg, and J. Mount. 2004. Managing surface water-groundwater to restore fall flows in the Cosumnes River. Journal of Water Resources Planning and Management-Asce 130, no. 4: 301-310.

Gallardo, A.H., A. Marui, S. Takeda, and F. Okuda. 2009. Groundwater supply under land subsidence constrains in the Nobi Plain. Geosciences Journal 13, no. 2: 151-159.

Greskowiak, J., H. Prommer, G. Massmann, C.D. Johnston, G. Nutzmann, and A. Pekdeger. 2005. The impact of variably saturated conditions on hydrogeochemical changes during artificial recharge of groundwater. Applied Geochemistry 20, no. 7: 1409-1426.

Hanson, R.T. 2003. Geohydrologic Framework of Recharge and Seawater Intrusion in the Pajaro Valley, Santa Cruz and Monterey Counties, California. Sacramento, California: U.S. Geological Survey.

Harou, J.J., and J.R. Lund. 2008. Ending groundwater overdraft in hydrologic-economic systems. Hydrogeology Journal 16, no. 6: 1039-1055

Harvey, F.E., J.F. Ayers, and D.C. Gosselin. 2007. Ground water dependence of endangered ecosystems: Nebraska's eastern saline wetlands. Ground Water 45, no. 6: 736-752.

Hatch, C.E., A.T. Fisher, C.R. Ruehl, and G. Stemler. 2010. Spatial and temporal variations in streambed hydraulic conductivity quantified with time-series thermal methods. Journal of Hydrology 389, nos. 3-4: 276-288.

Hatch, C.E., A.T. Fisher, J.S. Revenaugh, J. Constantz, and C. Ruehl. 2006. Quantifying surface water-groundwater interactions using time series analysis of streambed thermal records: Method development. Water Resources Research 42, no. 10: W05006. 
Heilweil, V.M., D.K. Solomon, and P.M. Gardner. 2007. Infiltration and recharge at Sand Hollow, an upland bedrock basin in Southwestern Utah. In Ground-Water Recharge in the Arid and Semiarid Southwestern United States, ed. D.A. Stonestrom, J. Constantz, T.P.A. Ferre, and S.A. Leake, 221-251. Reston, Virginia: U.S. Geological Survey.

Hoover, J.R. 1990. Seep and runoff detector design and performance to determine extent and duration of seep runoff zone from precipitation on hillsides. Transactions of the Asae 33, no. 6: 1843-1850.

Izbicki, J.A., A.L. Flint, and C.L. Stamos. 2008. Artificial recharge through a thick, heterogeneous unsaturated zone. Ground Water 46, no. 3: 475-488.

Massmann, G., J. Sultenfuss, U. Dunnbier, A. Knappe, T. Taute, and A. Pekdeger. 2008. Investigation of groundwater a residence times during bank filtration in Berlin: Multi-tracer approach. Hydrological Processes 22, no. 6: 788-801.

Prommer, H., and P.J. Stuyfzand. 2005. Identification of temperature-dependent water quality changes during a deep well injection experiment in a pyritic aquifer. Environmental Science \& Technology 39, no. 7: 2200-2209.

Quinn, P.F., and K.J. Beven. 1993. Spatial and temporal predictions of soil-moisture dynamics, runoff, variable source areas and evapotranspiration for Plynlimon, MidWales. Hydrological Processes 7, no. 4: 425-448.

Reinelt, P. 2005. Seawater intrusion policy analysis with a numerical spatially heterogeneous dynamic optimization model. Water Resources Research 41, no. 5: W10410.
Ronan, A.D., D.E. Prudic, C.E. Thodal, and J. Constantz. 1998. Field study and simulation of diurnal temperature effects on infiltration and variably saturated flow beneath an ephemeral stream. Water Resources Research 34, no. 9: 2137-2153.

Scanlon, B.R., R.W. Healy, and P.G. Cook. 2002. Choosing appropriate techniques for quantifying groundwater recharge. Hydrogeology Journal 10, no. 1: 18-39.

Schmidt, C.M., A.T. Fisher, A. Racz, C.G. Wheat, M. Los Huertos, and B. Lockwood. 2011a. Rapid nutrient load reduction during infiltration of managed aquifer recharge in an agricultural groundwater basin: Pajaro Valley, California. Hydrological Processes. DOI: 10.1002/hyp.8320.

Schmidt, C.M., A.T. Fisher, A.J. Racz, B.S. Lockwood, and M. Los Huertos. 2011. Linking denitrification and infiltration rates during managed groundwater recharge. Environmental Science \& Technology. DOI: 10.1021/es2023626.

Werner, A.D., and C.T. Simmons. 2009. Impact of sea-level rise on sea water intrusion in coastal aquifers. Ground Water 47, no. 2: 197-204.

Winter, T.C., D.O. Rosenberry, and A.M. Sturrock. 1995. Evaluation of 11 equations for determining evaporation for a small lake in the north central United States. Water Resources Research 31, no. 4: 983-993.

Zektser, S., H.A. Loaiciga, and J.T. Wolf. 2005. Environmental impacts of groundwater overdraft: Selected case studies in the southwestern United States. Environmental Geology 47 , no. 3: 396-404. 